\title{
Get wise to the web
}

Last month, the US news magazine Time was forced to relaunch a poll on its website concerning the public perception of genetically modified foods after bogus votes artificially skewed the results (http://www.pathfinder.com/time/daily/poll/0,2637,foodpoll2,00.html). According to Time, "large amounts of robotic voting during the past several weeks corrupted the poll's tally file," which subsequently had to be reset to zero.

Although Time did not reveal the culprits (a Y2K bug perhaps), in the 48 hours before alarm bells started ringing, the "very concerned" category of the poll swelled from $37 \%$ to $47 \%$, and the "not at all concerned" dropped from $35 \%$ to $29 \%$.

Once again, the anti-GM lobby has shown itself extremely adept and knowledgeable in exploiting the Internet for its own ends. This latest episode shows how a web-savvy strategy can very effectively publicize a message, whether by foul means or fair.

Indeed, "green" activists have been very busy on the Internet in recent months. In January, for example, Greenpeace sent out an e-mail alert urging recipients to deluge the US food company Kellogg's with copies of an article from US magazine Mother Jones criticizing "the lax standards of the US Food and Drug Administration" in regulating GM food. Around the same time, a similar e-mail alert was circulated during the FDA's recent public consultation on GM food, presumably in an effort to blitz the agency with critical comments.

One month before, antitechnology activists also used the web as a focal point for coordinating and organizing protests (among other things) against hormone-injected beef and corporate greed at the WTO conference in Seattle. Elsewhere, publicly spirited anarchists have set up web site to teach activists how to ruin transgenic crop trials (http://www.tao.ca/ ban/1299nighttimegardener.htm).

One certainly would be hard pressed to find biotechnology proponents who have used the web with as much creativity and efficiency. While several companies have established web sites that offer excellent didactic information on biotechnology (e.g., see www.AccessExcellence.com; www.novartis.com; www.monsanto.com)-and many others have sites that offer information on company commercial and R\&D activities-none really takes advantage of the real-time interactive nature of the web.

During the Swiss referendum on genetic engineering, the probiotechnology lobby understood to great effect the importance of improving the accessibility of scientists to the public, and the Internet was one of the ways in which they did this. Gen Suisse (www.gensuisse.ch/), an industry-sponsored site, was established to provide information on biotechnology as well as a direct means of accessing experts.

But so much more can be done. Accomplishing this will require a change in mindset from a model in which information is exchanged via a one-way process to one in which companies focus on directly interacting with the concerned public.

Web-wise activists have achieved much by weaving their own designs into the web. Biotechnology companies should now start to do the same.

\section{Gene therapy should welcome public scrutiny}

One would think that the fallout from the public relations disasters of the past year in agbiotechnology would have alerted gene therapists to the importance of allaying public anxieties concerning the risks (whether perceived or real) of their technology. Instead, judging by comments in some quarters, there appears to have been complacency and even irritation at the intense publicity surrounding the death of an 18-year-old patient in trials last year.

Some of this appears to stem from a (somewhat justified) feeling that the two overseeing regulatory agencies-the US National Institutes of Health's Recombinant DNA Advisory Committee (RAC) and the Food and Drug Administration (FDA)—should set their houses in order and provide clear guidelines for the disclosure of adverse events in trials. But it also appears to originate from a perception that the increased scrutiny of regulatory agencies and the public at large is a nettling development that will stifle progress of research and commercial development of the technology.

Some positive things have come from this unfortunate affair. For one thing, James Wilson, who heads the Institute for Gene Therapy, where the trial was carried out, has emerged with considerable dignity. In addition, the RAC (as well as the FDA) has now clarified its requirement for notification of all serious adverse events.

On the other hand, several notable researchers have revealed a disconcerting lack of awareness of the importance of public confidence for ensuring the future success and acceptance of gene therapy. For example, at a press briefing during the recent "Biology of Drug Discovery" symposium at the Whitehead Research Institute, a highprofile researcher denied that the gene therapy deaths were a cause for major concern, asserting that research should continue as normal. Apparently, the only message to be taken from the whole ruckus was that there is still a lot of basic biology to learn when it comes to how the body responds to foreign genetic material.

In November, at the Nature Biotechnology Gene Therapy symposium in Washington, a representative from a large multinational pharmaceutical company was overheard railing about the inexperience of the RAC in overseeing clinical trials. The implication clearly was that the blame for the recent bad press lay with RAC, not with the reluctance of corporate researchers to disclose adverse events.

With the prospect of new technologies and vectors coming to the clinic in the near future, gene therapists must accept the interest of the public in their technology. These are experimental technologies and knowledge of the basic biology is still evolving; little wonder, then, that the regulatory framework is less than perfect and also evolving.

Researchers must not only accept the right of regulators to scrutinize their protocols, but also acknowledge the importance of open public debate on the benefits and risks of gene therapy. To do anything less risks a loss of public confidence. And once public confidence has been lost, it cannot easily be recaptured. 